\title{
Communication Breakdown: The Media Effects on Ecuador's Environment
}

\author{
Sean da Silva* \\ Grant MacEwan University, Canada
}

\begin{abstract}
Environmental communication is an essential part of any society; it informs the population of new occurrences and happenings nearby, and around the globe. As technology evolves, so do the methods in which humans communicate and comprehend. The ways environmental issues are presented to and perceived by the public have increasingly influenced their decision making and continue to affect the way people live their lives. But what role do media outlets play in the environmental awareness of their audience? This research study demonstrates the importance of environmental communication in Ecuador and the various ways in which it can be distorted or controlled. It is critical that individuals are aware of their country's actions and reactions to the environment, as well as their own personal footprints within it. Researching the media in Ecuador, alongside the population's reaction to it, shows how important media is to the environmental awareness of its citizens, as well as their attitude towards conservation.
\end{abstract}

\section{Introduction}

As the world's population rises and resources deplete, it is important that citizens are aware of the decisions regarding the allotment of resources, as well as the internal and external behaviours of their government. The condition of the planet has become a major issue over the last few decades and continues to grow in public and political 
interests. But what role do media outlets play in the environmental awareness of their audience? Humans no longer live in a world of confinement, but instead a world of interconnectedness where actions affect more than just those who commit them. Because of an increasing demand for resources and the unavoidable repercussions that follow suit, such as war and human suffering, it is imperative that individuals are informed and aware of the current environmental situation. With the mass media being a major component in the distribution of this knowledge, it would seem essential that it is available to all those who desire it. Yet, with a closer examination of the distribution of knowledge and information within a population, it is evident there is a clear disconnect.

Focusing on some of the environmental issues affecting our planet, such as deforestation, water contamination, and the consumption of Earth's fossil fuels, humans can see how a lack of communication in the environmental sector could lead to some unwarranted occurrences to take place with little to no confrontation. When people are uninformed or unaware of what is taking place in their own country, it is difficult for them to say or do anything about it. As a result of this unknowing, a country can be devastated by external and internal influences, as is the case in Ecuador. With one of the highest biological diversity in the world, Ecuador is a prime target for the acquisition of resources. A major exporter of both oil and timbre, the country has been constrained to destroy its ecosystem, due to decades of financial and administrative instability (Rochlin 2011), for its economic well-being. This disregard for preservation by Ecuador's population is not purely an act of malice or greed, but an act of survival. By examining Ecuador's development in the sectors of extraction and communication, coupled with data collected in Ecuador, this research study explores the potential correlation between limits or manipulation of communication within Ecuador, and the environmental issues it faces today.

\section{Background}

The Republic of Ecuador is a South American country that shares a border with Columbia and Peru, and is both a diverse and valuable part of the planet. With a turbulent history of development, Ecuador has been "marked by a pronounced reliance on the primary sector, from cocoa to bananas, and most recently to a focus on the extractive industry within the context of the global commodity boom of the new millennium" (Rochlin, 2011, p. 11). With a strong dependence on extractive activities, such as oil extraction, deforestation, and mining, Ecuador's economy relies significantly on the exportation of these resources and the revenue it generates-primarily the oil 
sector which "typically accounts for 50\%-60\% of the country's export earnings, $15 \%$ $20 \%$ of GDP, and $30 \%-40 \%$ of government revenues" (U.S Department of State).

It is difficult for a country like Ecuador, with a heavy reliance on extractive revenues, to eliminate its major sources of income; however, it is not what is being extracted, but how it is being extracted and at what cost that are of concern. The majority of oil in Ecuador is situated beneath its tropics. This large scale destruction of Ecuador's tropical areas is a global concern, as the Amazon rainforest plays a significant role in climate change, global weather, and oxygen production (Britannica Encyclopedia, 2012). In 1989, a government study reported that "spills from flow lines were dumping an estimated 20,000 gallons every two weeks. As well, in another study in 1992 the government recorded 30 major spills totalling 16.8 million gallons of crude oil. About 30 billion gallons of toxic wastes and crude oil are estimated to have been discharged into the Orient' (Rochlin, 2011 p. 20). With media being an important link in informing the public, the possibility of important environmental information being distributed unevenly amongst Ecuador's citizens is significant. It is difficult to believe a population would allow its government to commit large scale ecological damage with minimal opposition; however, in an underdeveloped country where private operators dominate the media and the majority of the population rely on private

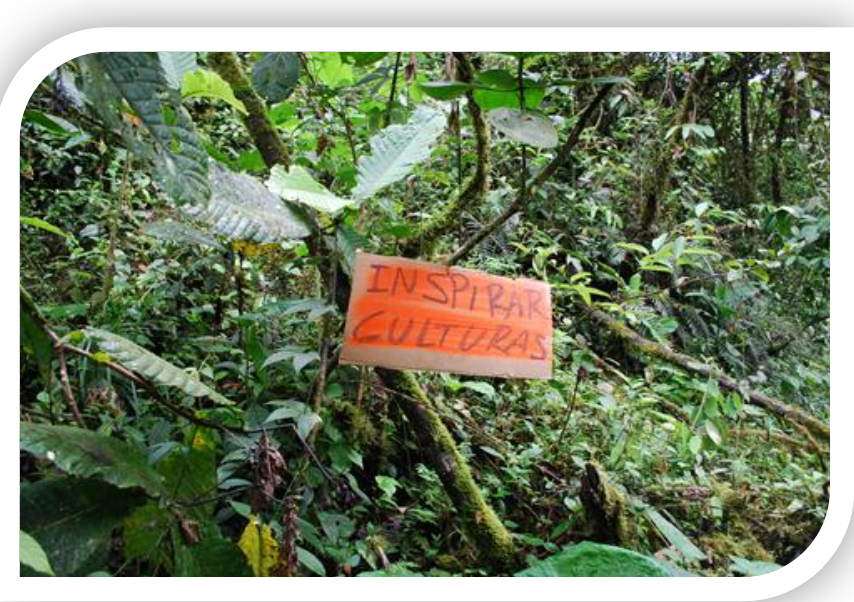

Figure 1. Inspiration found in the Ecuadorian Amazon radio (CIA Factbook, 2007), one of the factors that has enabled such actions to take place virtually unchallenged is the lack of information that has been provided to the citizens with respect to environmental activities.

Although Ecuador has strived to maintain a level of stability in the past, the country has recently started

to see progress in many fields. Ecuador's communications have improved over the last few years as the country has seen a marked rise in usage and accessibility. Media consumption has risen steadily since 2006, with a 600\% increase in broadband internet subscribers between 2008 and 2009 (CIA World Factbook, 2009). Still, with a steady rise in technology and communication, a developing nation has difficulty providing these 
services to everyone, particularly the rural areas outside the major urban centers. This is the case for many individuals and can become a burden to those who live in areas without access who wish to have a global voice.

\section{Discussion and Results}

With a growing reliance on media and technology, individuals have compromised their ability to interpret messages according to their own learned beliefs and values. According to Trenholm (2011), this reliance to media and technology is part of a powerful effects model, "where receivers are relatively passive; they accept media messages at face value and unconsciously allow media sources to tell them what to do" (p. 287). This is a major issue in societies today, as people are influenced by what they hear and see on television or radio. A reliance on technology is a reliance on convenience. People who rely on convenience no longer feel the need to seek out their news or information, but rely on quick and accessible sources for reference. The majority of these sources, although reputable, have moved individuals to become more involved in popular affairs, while simultaneously shutting them off from issues they consider unimportant. This limited scope of information is a consequence of convenience.

\section{Research Methodology}

In this mixed methods research study, statistical and interpretive methods of scientific inquiry needed to answer the study's research question were examined: What

role do media outlets play in the environmental awareness of their audience? With a balance between quantitative and qualitative research, triangulation of data was achieved. When comparing observations (e.g. local media usage) to previously documented statistics (Encyclopedia Britannica, 2012; CIA Factbook, 2007; Rochlin, 2011), it allowed for more in-depth data and conclusions.

The quantitative sample strategy consisted of a collection of statistics compiled from multiple scholarly peer-reviewed sources. The major focus points for the quantitative samplings included a collection of recent statistics demonstrating the popular media usage throughout the region, as well as recent statistics and/or news concerning Ecuador's ecosystem, and local environmental happenings. The qualitative sample strategy was a typical case which consisted of interviews completed by a questionnaire developed specifically for the study. The interviews were conducted face-to-face with four participants. The intention of this sample was to acquire local insights on the environmental situation in Ecuador combined with popular media usage. The extent of 
the proposed sample was minimal due to time restraints. Sample participants were chosen based on communication skills and availability. Fieldwork was conducted in Ecuador in the form of interviews with locals who were able to read/write/speak English. This allowed the data collected from their responses to be clear and accurate.

Table 1: Total Sample Results

\begin{tabular}{|c|c|}
\hline \multicolumn{2}{|c|}{ Total Sample Results of the Study } \\
\hline Questions & Results \\
\hline $\begin{array}{l}\text { 1. What local media do you use (i.e. } \\
\text { TV, radio, internet, newspaper) } \\
\text { to learn about what is happening } \\
\text { in Ecuador? }\end{array}$ & $\begin{array}{l}\text { - Irrelevant of their location (urban or rural), the } \\
\text { major source for news and information amongst } \\
\text { the participants was the internet. }\end{array}$ \\
\hline $\begin{array}{l}\text { 2. Do your local media report } \\
\text { information about the } \\
\text { environment in Ecuador? }\end{array}$ & $\begin{array}{l}\text { - Yes, local media report information about the } \\
\text { environment, but only major issues and events. }\end{array}$ \\
\hline $\begin{array}{l}\text { 3. How does your government } \\
\text { communicate environmental } \\
\text { decisions within Ecuador? }\end{array}$ & $\begin{array}{l}\text { - The government often discusses the positive } \\
\text { attributions they make for improvement with a } \\
\text { focus on major issues. }\end{array}$ \\
\hline $\begin{array}{l}\text { 4. What are your thoughts on } \\
\text { Ecuador's ecosystem and } \\
\text { environment? }\end{array}$ & $\begin{array}{l}\text { Even with initiatives pushing for conservation } \\
\text { and protection, the overall outlook is } \\
\text { unfavorable as progress in all fields is dilatory. }\end{array}$ \\
\hline $\begin{array}{l}\text { 5. If you could, what would you } \\
\text { change in the way that } \\
\text { environmental information is } \\
\text { communicated in Ecuador? }\end{array}$ & $\begin{array}{l}\text { - A system of communication which is } \\
\text { administered, and not governed, would help } \\
\text { eliminate the manipulation and corruption of } \\
\text { information. }\end{array}$ \\
\hline
\end{tabular}

In this section, the results from the interviews conducted while in Ecuador using the questionnaire, The Media Effects on Ecuador's Environment Questionnaire, are presented using the responses from all (four) participants. All participants interviewed were over 18 years of age, and had been living in Ecuador for more than three years. Participants One and Two lived in rural areas in Ecuador's Amazon, while participants Three and Four lived in urban centers.

\section{Media in Ecuador}

The Media Effects of Ecuador's Environment Questionnaire consisted of five questions which focused on the participant's standpoint on Ecuador's current media, and environmental stance. Questions 1 and 2 focused on the participant's media usage, TV, radio, internet, newspaper, and were used to determine which media was the most reliable and accessible for them. Questions 3 and 4 were aimed at the participants 
understanding of the current environmental situation within Ecuador, and asked how their government communicated environmental decisions regarding Ecuador's ecosystem and environment. Question 5 was used to determine what the participants believed would be a more successful way of communicating environmental information within Ecuador then the current system.

The results of each question are presented below.

Question 1: What local media do you use (i.e. TV, radio, internet, newspaper) to learn about what is happening in Ecuador?

All (four) participants stated that the internet was their primary source for news and information in Ecuador. Participants One and Two claimed that due to their remote location in the Ecuadorian Amazon they had very few options other than the internet, public radio, or television, and that the majority of inhabitants who occupy similar areas, who do not have access to the internet, rely on radio or television for news. Participants Three and Four stated that they use a variety of media in their urban centers, including local and national newspapers and television stations. However, the internet was the most popular source of media for all participants.

Question 2: Do your local media report information about the environment in Ecuador?

When asked about the environmental coverage by local media, all participants claimed it was a popular issue in Ecuador, but only major events were a topic of discussion. When asked about his local media, participant Four claimed that "stories deemed insignificant such as minuscule oil spills, small scale deforestation, and human grievances, were seldom discussed." All (four) participants stated that both public and private spheres of the media include ecological elements in their reports; although some sources, such as television and newspapers, contain more than others.

Question 3: How does your government communicate environmental decisions within Ecuador?

As a fundamental issue of discussion in Ecuador, the environment should be a major concern for most Ecuadorians. The general consensus among the participants was that the local media within Ecuador is "biased, watered down, and not worth watching/reading/listening to" (participant Three). Each believes the information released is administered by the government — which does not allow for many opinion pieces or freedom of the press. Within the two sectors, the participants found that the public sphere generally discusses the positive aspects the government does for the 
country, reluctant to release any details of negative occurrences. Participant Four believed the public sphere "acts as a cheerleader for the government; telling you all the positive things they do for Ecuadorians. The public sphere is reluctant to say negative things, relying on the positive attributes, such as infrastructure and medicine, in order to suppress the minute negative aspects." The participants believe that because the government is influential in so many of the media outlets, it causes parts of the country to receive a constant flow of propaganda.

Question 4: What are your thoughts on Ecuador's ecosystem and environment?

The overall attitude of the participants towards Ecuador's current environmental situation was dismal. Each believed that things are heading in the right direction but with very limited progress. With the Amazon being allocated in sections to the oil companies, participants One and Two believe it is only a matter of time before the entire Amazon is desecrated. With one of the highest biological diversity in the world, they would like to see a much larger focus placed on the preservation and protection of Ecuador's natural habitat. Participant Two, when asked about the state of the Orient, and the destruction being caused by local residents claimed that, "Ecuador loves life, but when it comes down to it, people will do anything it takes to survive, even if that means destroying what they love."

Question 5: If you could, what would you change in the way that environmental information is communicated in Ecuador?

All (four) participants believe that the current system of communication in Ecuador is inconsistent. They feel that the media needs to look at the whole picture and not just focus on small facets of issues, but inform the population of the current issues that affect them, and everyone around them. This question, in particular, caused the participants to become quite emotional, as they were very passionate in their responses. A reoccurring response from all [four] participants was the need for more sustainable development and a greater interest in environmental education. Participant Three said there is a need for more initiatives, such as the ITT International Initiative meant to preserve the Yasuni national park in the Amazonian Ecuador, and create a better market for green technology. 


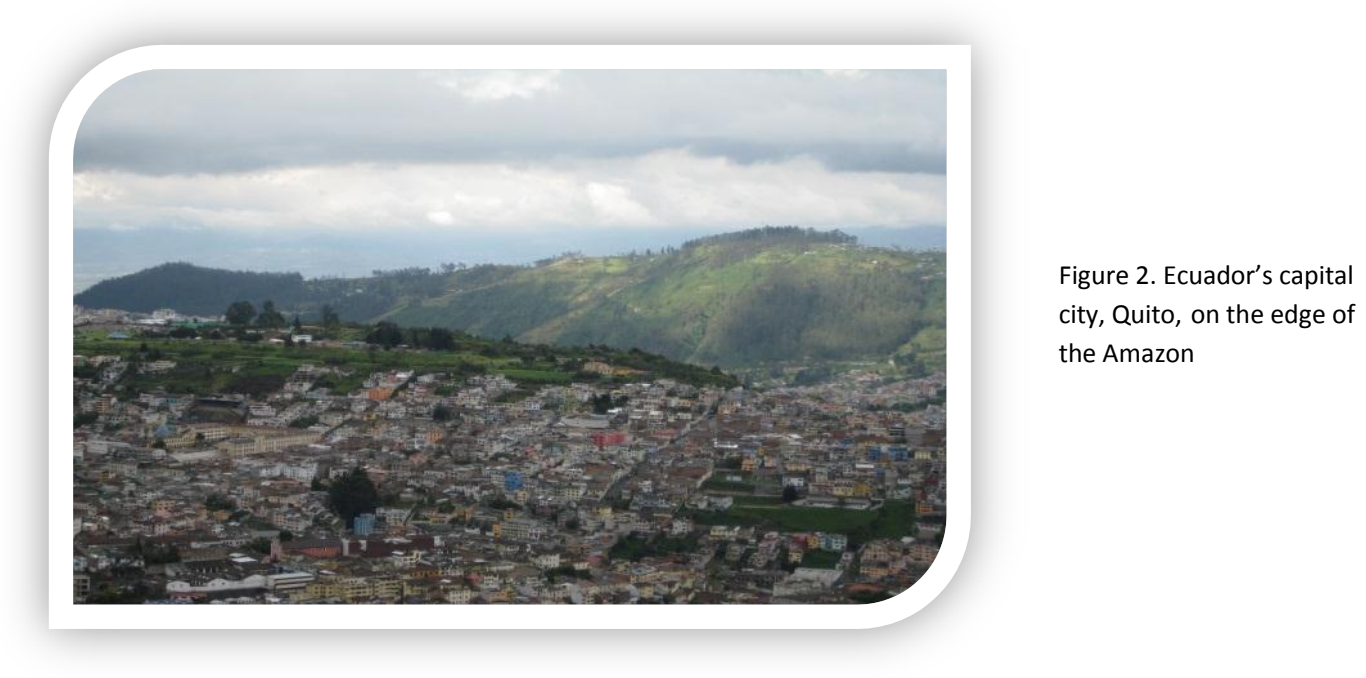

\section{Results}

\section{Freedom of the Press}

People do not have time to read, watch, or listen to everything that takes place around them; sometimes they make more of an effort than others, but most of the time people rely on the media to fill them in with what is going on. The problem with a high population dependency on local media is that any manipulation or corruption that takes place within the system can have serious side effects on the general public.

Ecuador has grown significantly in the media department over the last few years, with online accessibility at a significant high, and online subscribers growing annually. However, this dramatic spike in online usage is not directly caused by the introduction of new technology, but is the response of a population skeptical of their government's influence on the information released. According to Rochlin (2011), "the Ecuadorian government in December 2009 temporarily cancelled the radio broadcasting licence for the Shuar Indians, who had used broadcasts to protest against planned oil and mining activities in the province of Morona Santiago" (p. 31). This demonstrates the government's ability to control what is being accessed or broadcasted by the population, and an example of manipulation within the government.

Participant Four in the interview process stated that "verbal and legal attacks against the press by President Rafael Correa and his government increased significantly during the year 2009, causing relations between the press and the government to deteriorate and reports of indirect censorship and self-censorship to increase." This has become a major 
topic of discussion within Ecuador as the issue has received international attention. An article in the July 2011 issue of The Economist discusses Ecuador's President, Raphael Correa, taking a columnist from El Universo, Ecuador's largest newspaper distributor, to court for allegedly defacing him in a recent article. A judge ended up ruling in favour of Correa sentencing the columnist, and El Universo's three directors, to three years in prison and ordered them to pay $\$ 40$ million in damages (The Economist, 2011, para. 4). It is due to the legal actions taken by the government that have caused an automatic censorship to take place amongst the local media in fear of being reprimanded. This fear of government encroachment has affected the quality of news being released within Ecuador, and has silenced the opinions of many journalists.

This issue is a major reason why the participants chose not to rely on local media for updates on news and information, but looked to alternate sources, such as the internet and national news stations, in order to access their information. This leaves individuals with limited access to alternate media sources outside of Ecuador unable to freely choose where and how they receive their news and information.

\section{Media Accessibility}

The world changes perpetually before our eyes, and so do the various ways in which we communicate and comprehend within it. We are living in the age of technology, and are either blessed by its evolution or cursed by it. With advancements in communication technology it would seem reasonable that everyone would have the opportunity to know what is happening around the world - let alone their own backyard. Yet, with so many mediums available, it is hard to believe that there are people still unaware of the activities that go on around them. Media is an important link that allows people to be informed and make intelligent decisions about how to live their lives. When you lack this information, it is difficult to take action.

The National Basin of Ecuador has a population of about 500,000 people, or just five percent of the country's total (Rochlin, 2011, p. 30). This small portion of Ecuador's population lives in an area of the county where access to technology is limited or otherwise non-existent, which causes the political interests and opinions of those in the area to be overlooked. The deficiency of communication throughout the remote regions of Ecuador cause issues within the community, as people, and their opinions, tend to be ignored because they lack the necessary tools to communicate them. A separation in technology eventually leads to a separation in community as individuals go unheard, and unnoticed. With the vast majority of extractive activities taking place in the Orient, away from any major centers, it would seem essential that the individuals who occupy these 
areas would have the opportunity to voice their concerns regarding the environmental situation as it affects them firsthand. Yet, with limited access to communicative technologies they have become trapped in a precarious existence with little to no help.

The issue of separation within the community is apparent between the rural and urban populations in Ecuador. The distinguishing element of the two, in terms of media, is the superior quality and quantity of media available to the urban communities at any given point. With media outside the major cities of Ecuador being so scarce (due to small populations) there is a reliance on public television and radio for news and information. There are no other alternatives available to individuals without internet access who want to seek alternate viewpoints, or to voice their own.

\section{Conclusion}

The Earth is changing at an accelerating rate, so it is important that humans consider their role in the process and remain humble to its activities. When examining environmental issues, it is implausible to link every event to human behaviour, but it is not prudent to dismiss human involvement all together. Human activities affect the planet in some form or another, so it is imperative that people are aware of their impact, and recognize the things they can do, or avoid doing, to reduce that impact. However, not all environmental issues are thought to be of social, political, or legislative importance. Problems and issues become recognized through talk, communication, and discourse, which define or constrict them as problems or issues for public and political concern (Hansen, 2010, p. 8). As communication plays an increasingly important role in the environmental awareness of the Earth's population, it is imperative that these systems of communication are regulated and controlled in order to eliminate manipulation. It is only by working together as a unified society that the people's perceptions of the Earth will turn from profit - to protect.

*Writer: Sean da Silva in a second year student from the Bachelor of Communication Studies program at Grant MacEwan University, Canada. He has a keen interest in human behavior and cultural studies, and is an extensive world traveller. He is passionate about the environment and strives for a prosperous, more sustainable future. 


\section{References}

Rochlin, J. (2011). Development, the Environment and Ecuador's Oil Patch: the Context and Nuances of the Case Against Texaco. Journal of Third World Studies, 28(2), 11-39.

CIA world factbook [electronic resource]. (2009). Washington D.C.: Central Intelligence Agency.

Hansen, A. (2010). Environment, Media and Communication.New York, NY: Routledge.

The Economist. (July 22, 2011). Freedom in the in Ecuador [online resource]. Retrieved from http://www.economist.com/blogs/americasview/2011/07/freedom-pressecuador.

Trenholm, S. (2011).Communication Through Communication: An Introduction to the Study Of buman Communication. Boston, MA: Allyn \& Bacon.

Encyclopaedia Britannica. (2012). Boston, Mass.: Credo Reference. 